\title{
Cobalt-Mediated Radical Copolymerization of Vinylidene Fluoride and 2,3,3,3-Trifluoroprop-1-ene
}

\author{
Panagiotis G. Falireas and Bruno Ameduri * (D) \\ ICGM, Univ. Montpellier, CNRS, ENSCM, 34095 Montpellier, France; pfalireas@uliege.be \\ * Correspondence: bruno.ameduri@enscm.fr
}

\begin{abstract}
New copolymers based on vinylidene fluoride (VDF) and 2,3,3,3-tetrafluoroprop-1-ene (1234yf) were synthesized by organometallic-mediated radical copolymerization (OMRcP) using the combination of bis(tert-butylcyclohexyl) peroxydicarbonate initiator and bis(acetylacetonato)cobalt(II), $\left(\mathrm{Co}(\mathrm{acac})_{2}\right)$ as a controlling agent. Kinetics studies of the copolymerization of the fluoroalkenes copolymers were monitored by GPC and ${ }^{19} \mathrm{~F}$ NMR with molar masses up to $12,200 \mathrm{~g} / \mathrm{mol}$ and dispersities $(\boxplus)$ ranging from 1.33 to 1.47. Such an $\mathrm{OMRcP}$ behaves as a controlled copolymerization, evidenced by the molar mass of the resulting copolymer-monomer conversion linear relationship. The reactivity ratios, $\mathrm{r}_{\mathrm{i}}$, of both comonomers were determined by using the Fineman-Ross and KelenTüdos fitting model leading to $\mathrm{r}_{\mathrm{VDF}}=0.384 \pm 0.013$ and $\mathrm{r}_{1234 \mathrm{yf}}=2.147 \pm 0.129$ at $60^{\circ} \mathrm{C}$, showing that a lower reactivity of VDF integrated in the copolymer to a greater extent leads to the production of gradient or pseudo-diblock copolymers. In addition, the $\mathrm{Q}(0.03)$ and e (0.06 and 0.94) parameters were assessed, as well as the dyad statistic distributions and mean square sequence lengths of PVDF and P1234yf.
\end{abstract}

Citation: Falireas, P.G.; Ameduri, B. Cobalt-Mediated Radical Copolymerization of Vinylidene Fluoride and 2,3,3,3-Trifluoroprop-1-ene. Polymers 2021, 13, 2676. https://doi.org/10.3390/ polym13162676

Academic Editors: James Bowen and Gregory T. Russell

Received: 23 July 2021

Accepted: 6 August 2021

Published: 11 August 2021

Publisher's Note: MDPI stays neutral with regard to jurisdictional claims in published maps and institutional affiliations.

Keywords: 3,3,3-tetrafluoroprop-1-ene; cobalt acetylacetonate; controlled radical polymerization; kinetics of copolymerization; organometallic radical copolymerization; RDRP; reactivity ratios; vinylidene fluoride

\section{Introduction}

Fluoropolymers are outstanding specialty polymers which exhibit remarkable properties for High Tech applications [1-4]. Most fluorinated homopolymers display a high crystallinity rate (higher than $95 \%$ for PTFE) that makes them insoluble in many common organic solvents and further induces energetic processing costs to melt or sinter them [5]. Thus, copolymerizing fluoroalkenes overcome these limitations while also enabling better solution characterization. In fact, copolymers of vinylidene fluoride (VDF) have led to many studies and patents [6-8]. Among all VDF comonomers, 2,3,3,3-trifluoropropene, HFO-1234yf $\left(\mathrm{CF}_{3} \mathrm{CF}=\mathrm{CH}_{2}\right)$ is a valuable example of $\mathrm{HFO}$ class because it has a low global warming potential $\left(\mathrm{GWP}_{100 \mathrm{yrs}}<1\right)$, a Montreal Protocol-regulated substance with high $\mathrm{CO}_{2}$-eq emissions, used in mobile air conditioning [9-11]. Indeed, a few radical copolymerizations of VDF with $1234 \mathrm{yf}$ have been reported, either by conventional radical copolymerization [12-14] or under reversible deactivation radical copolymerizations (RDRP), either by iodine transfer copolymerization [15] or RAFT [16]. However, to the best of our knowledge, although VDF has been successfully polymerized by cobalt-mediated radical polymerization (CMRP) $[17,18]$, and although that technique can be well-applied on the copolymerization of vinyl acetate (VAc) [19], no study has been achieved on the CMR copolymerization of VDF with 1234yf. Wang et al. [20] reported the CMR copolymerization of chlorotrifluoroethylene (CTFE) with VAc initiated by AIBN in the presence of bis(acetylacetonato)cobalt(II), $\mathrm{Co}(\mathrm{acac})_{2}$, as a controlling agent. Though both molar masses and molar compositions of the resulting copolymers could be "controlled", $Ð$ values of the resulting copolymers were high ( 1.57). Hence, the objective of this present study 
aims at copolymerizing VDF with $1234 \mathrm{yf}$ in controlled conditions by simply using a peroxycarbonate initiator and $\mathrm{Co}(\mathrm{acac})_{2}$ as a mediated compound to favor the control of such a reaction. Recently, the current authors have investigated and optimized the polymerization conditions of OMRP of VDF by redox initiation, initiated by bis(tert-butylcyclohexyl) peroxydicarbonate (P16) and $\mathrm{Co}(\mathrm{acac})_{2}$ as a controlling agent [17]. All polymerizations were carried out in dimethyl carbonate (DMC), a suitable solvent for PVDF oligomers that also exhibits fast rate of VDF polymerization [21]. By applying the same conditions, we investigated the copolymerization of VDF with 1234yf (Scheme 1). The results indicate that the process has the features of a controlled radical polymerization.
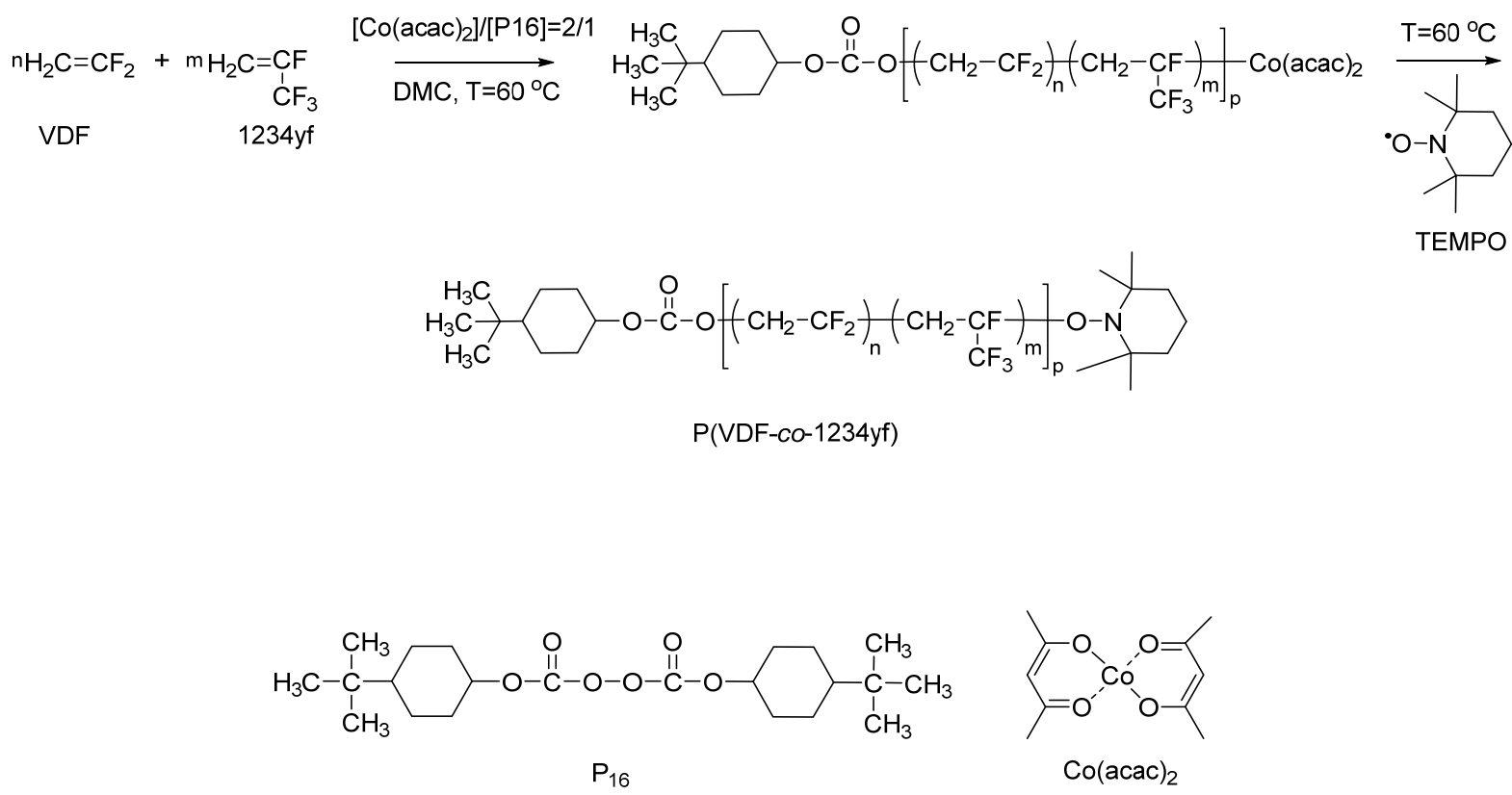

Scheme 1. Preparation of P(VDF-co-1234yf) copolymers by OMRP mediated by $\mathrm{Co}(\mathrm{acac})_{2}$ and initiated by bis(tertbutylcyclohexyl) peroxydicarbonate (P16).

\section{Results and Discussion}

\section{Copolymerization of VDF with $1234 y f$}

Recently, we reported that VDF could be homopolymerized by OMRP by redox initiation using the combination of $\mathrm{P} 16$ and $\mathrm{Co}(\mathrm{acac})_{2}$. The best control of the polymerization was found under optimized conditions $\left([\mathrm{P} 16]_{0} /\left[\mathrm{Co}(\mathrm{acac})_{2}\right]_{0}=2 / 1, \mathrm{~T}=60^{\circ} \mathrm{C}\right)$, leading to PVDF homopolymers with low dispersities $(\boxplus<1.35)$ [17]. Based on similar conditions, the copolymerization of VDF with 1234yf was performed, as illustrated by Scheme 1 .

In order to get a deeper insight into the copolymerization of VDF with $1234 \mathrm{yf}$, a kinetic study was performed covering the whole conversion of polymerization. Therefore, singlepoint experiments (ranging from $0.25 \mathrm{~h}$ to $16 \mathrm{~h}$ ) were carried out. All copolymerizations were conducted under similar conditions $\left([\mathrm{VDF}]_{0} /[1234 \mathrm{yf}]_{0} /[\mathrm{P} 16]_{0} /\left[\mathrm{Co}(\mathrm{acac})_{2}\right]_{0}=80 / 20 / 2 / 1\right.$ at $60{ }^{\circ} \mathrm{C}$ in DMC) and were monitored by ${ }^{19} \mathrm{~F}$ NMR (Figure 1) and GPC measurements equipped with a refractive index detector (Figure 2a). At this point, it should be stressed that in order to prevent unfavorable chain terminations, all polymerizations were quenched by TEMPO. According to the literature, TEMPO plays the role of a radical scavenger by displacing the covalently bonded $\mathrm{Co}(\mathrm{acac})_{2}$ moiety from the propagating active chains [22]. 


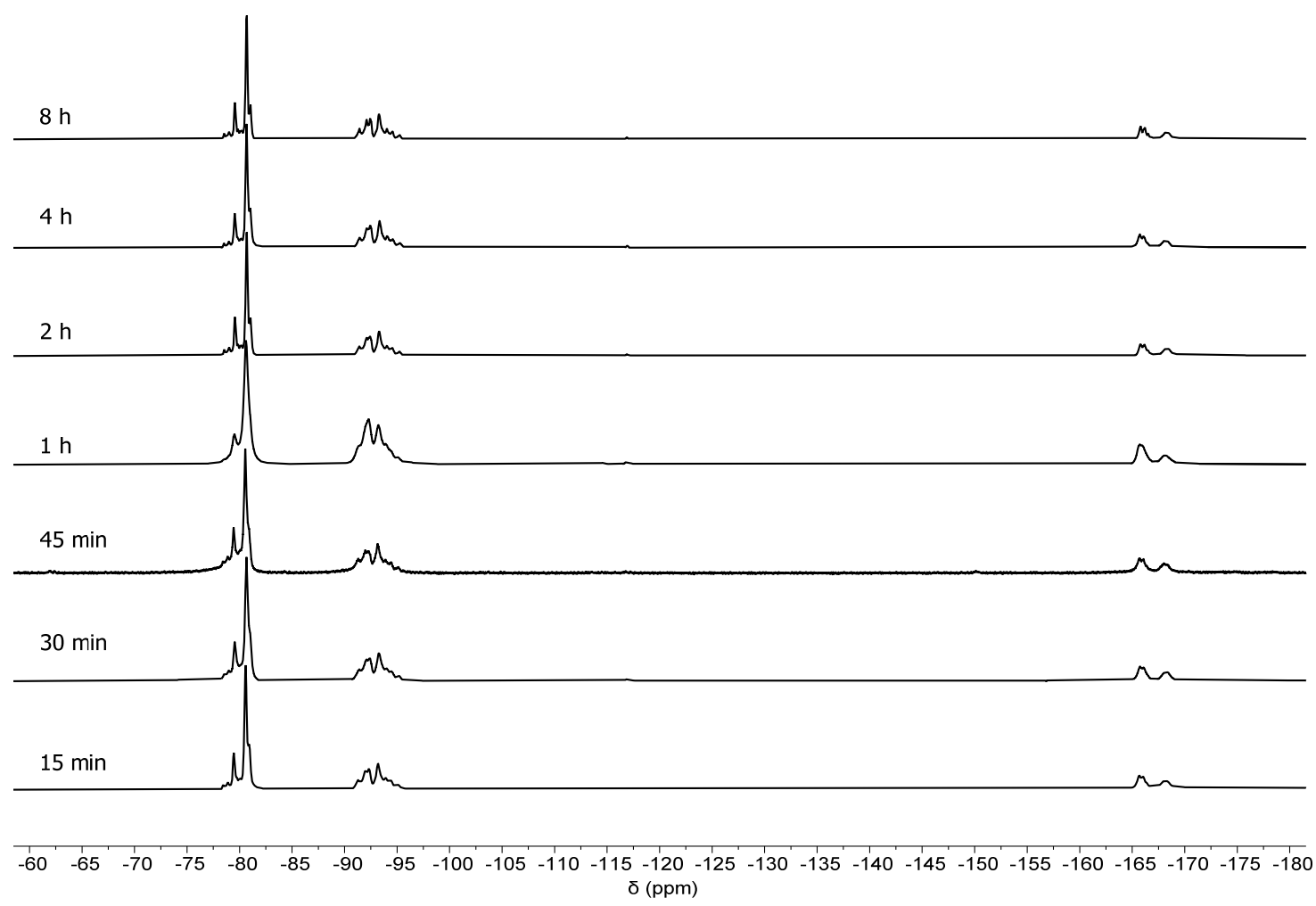

Figure 1. Stack of ${ }^{19} \mathrm{~F}$ NMR spectra recorded at $25{ }^{\circ} \mathrm{C}$ in $\left(\mathrm{CD}_{3}\right)_{2} \mathrm{CO}$ of $\mathrm{P}(\mathrm{VDF}-\mathrm{co}-1234 \mathrm{yf})$ copolymers at different polymerization times.

The GPC chromatograms of the synthesized copolymers exhibited negative refractive index $\left(\mathrm{n}_{\mathrm{D}}\right)$ signals since the $\mathrm{n}_{\mathrm{D}}$ increment of PVDF (and probably poly(1234yf)) in DMF is negative [23-25]. Their profile displayed unimodal distributions showing no sign of coupling reactions and they significantly shifted toward lower elution times throughout the polymerization. Figure $2 \mathrm{c}$ illustrates the evolution of $M_{n}$ and $Đ$ versus monomer conversion where the linear relationship between molar mass and conversion evidences that the chain growth has a controlled behavior. At the same time, dispersities increased progressively from 1.33 to 1.47 .

The semilogarithmic kinetic plot exhibited two different regimes (Figure 2b). Initially, a fast polymerization was observed without any sign of induction period which is expected for a redox initiating system [26]. The copolymerization proceeded at a fast rate for $1 \mathrm{~h}$, then it slowly decreased until it terminated after $8 \mathrm{~h}$ where the conversion reached $33 \%$. Similar polymerization kinetics were found for homopolymerization of VDF by OMRP performed under the same conditions, where the change of polymerization rate was retarded after $2 \mathrm{~h}$ probably due to limited solubility of PVDF in DMC at $60{ }^{\circ} \mathrm{C}[17,18]$, as well as in RAFT polymerization of VDF [27].

By means of ${ }^{19} \mathrm{~F}$ NMR spectroscopy and based on previously reported studies, it was possible to thoroughly characterize the P(VDF-co-1234yf) copolymers synthesized by $\mathrm{OMRcP}$ after quenching with TEMPO and purification.

The ${ }^{19} \mathrm{~F}$ NMR spectrum of P(VDF-co-1234yf) copolymers terminated at $8 \mathrm{~h}$ (Figure 3, Table 1, Entry 8) clearly displays a number of characteristic signals attributed to both comonomers: (i) the characteristic peaks ranging from -90.6 to $-95.4 \mathrm{ppm}$ correspond to the normal or Head-to-Tail (H-T) VDF-VDF dyads $\left(-\mathrm{CH}_{2}-\mathrm{CF}_{2}-\mathrm{CH}_{2}-\mathrm{CF}_{2}-\right)$ in the PVDF chains, while those at -114.6 and $-116.9 \mathrm{ppm}$ are attributed to the reverse or Head-toHead (H-H) VDF-VDF dyads (- $\left.\mathrm{CH}_{2}-\mathrm{CF}_{2}-\mathrm{CF}_{2}-\mathrm{CH}_{2}-\right)[6,7,23,25]$; (ii) signals from -95.4 to -92.7 ppm are assigned to $\mathrm{CH}_{2}-\mathrm{CF}_{2}-\mathrm{CH}_{2}-\overline{\mathrm{CF}}\left(\mathrm{CF}_{3}\right)-$; (iii) the trifluoromethyl and tertiary fluorine groups of $1234 \mathrm{yf}$ in the $-\mathrm{CH}_{2}-\mathrm{CF}_{2}-\mathrm{CH}_{2}-\mathrm{CF}\left(\mathrm{CF}_{3}\right)$ - dyads of the copolymer are assigned from -78 to $-82 \mathrm{ppm}$ and in the -164 to $-169 \mathrm{ppm}$ range, respectively; (iv) and 
finally, closer inspection in regime between from -66 to $-76 \mathrm{ppm}$ revealed the presence of a series of peaks which could be attributed to fluorine groups of VDF or 1234yf adjacent to TEMPO end groups $[17,18]$.
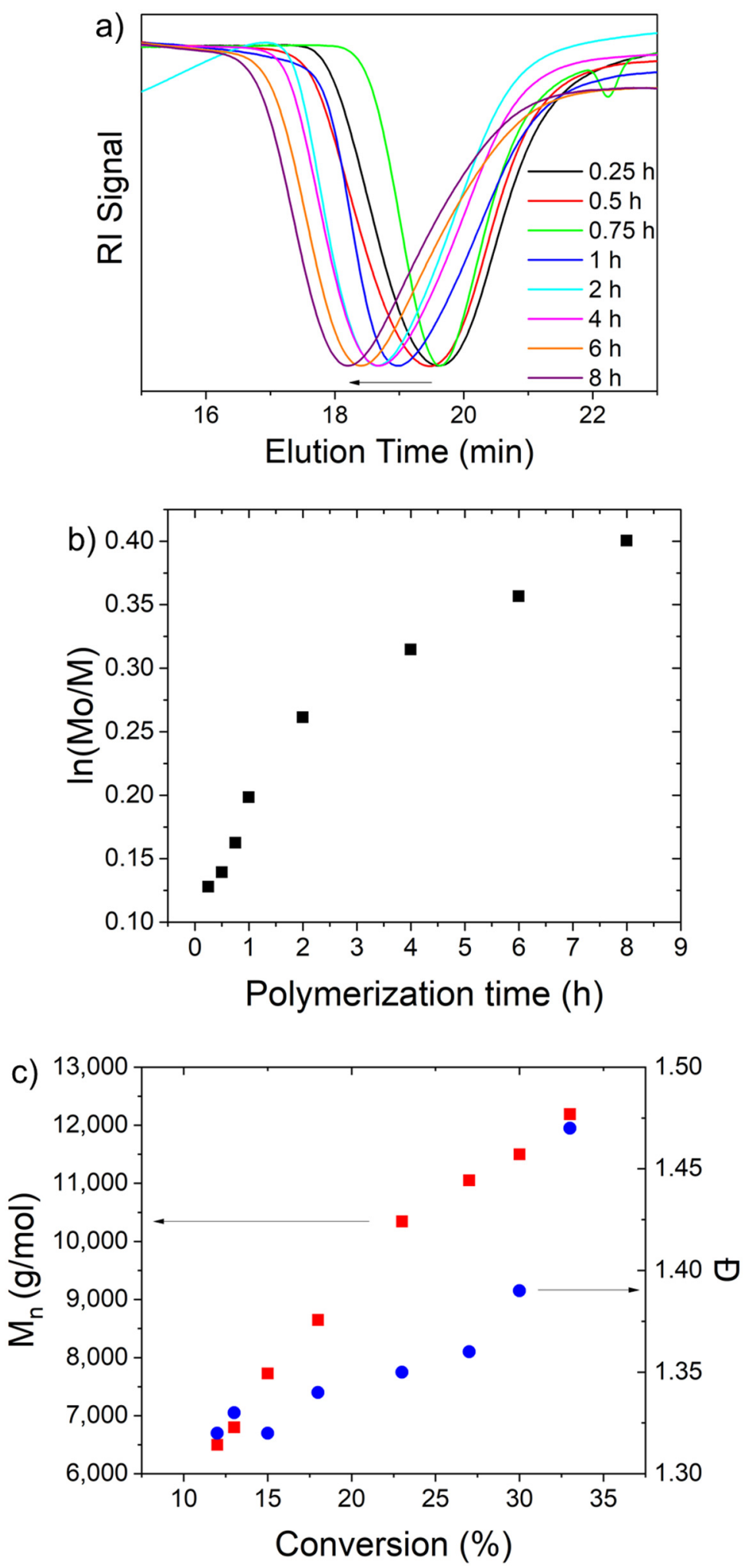

Figure 2. Plots of (a) GPC eluograms for the VDF/1234yf copolymerization via OMRcP, (b) $\ln \left([\mathrm{M}]_{0} /[\mathrm{M}]\right)$ vs. polymerization time, and (c) evolution of $M_{n}$ and $Đ$ vs. the comonomer conversions. Conditions $[\mathrm{VDF}]_{0} /[1234 \mathrm{yf}]_{0} /[\mathrm{P} 16]_{0} /\left[\mathrm{Co}(\text { acac })_{2}\right]_{0}=80 / 20 / 2 / 1$ at $\mathrm{T}=60{ }^{\circ} \mathrm{C}$. 


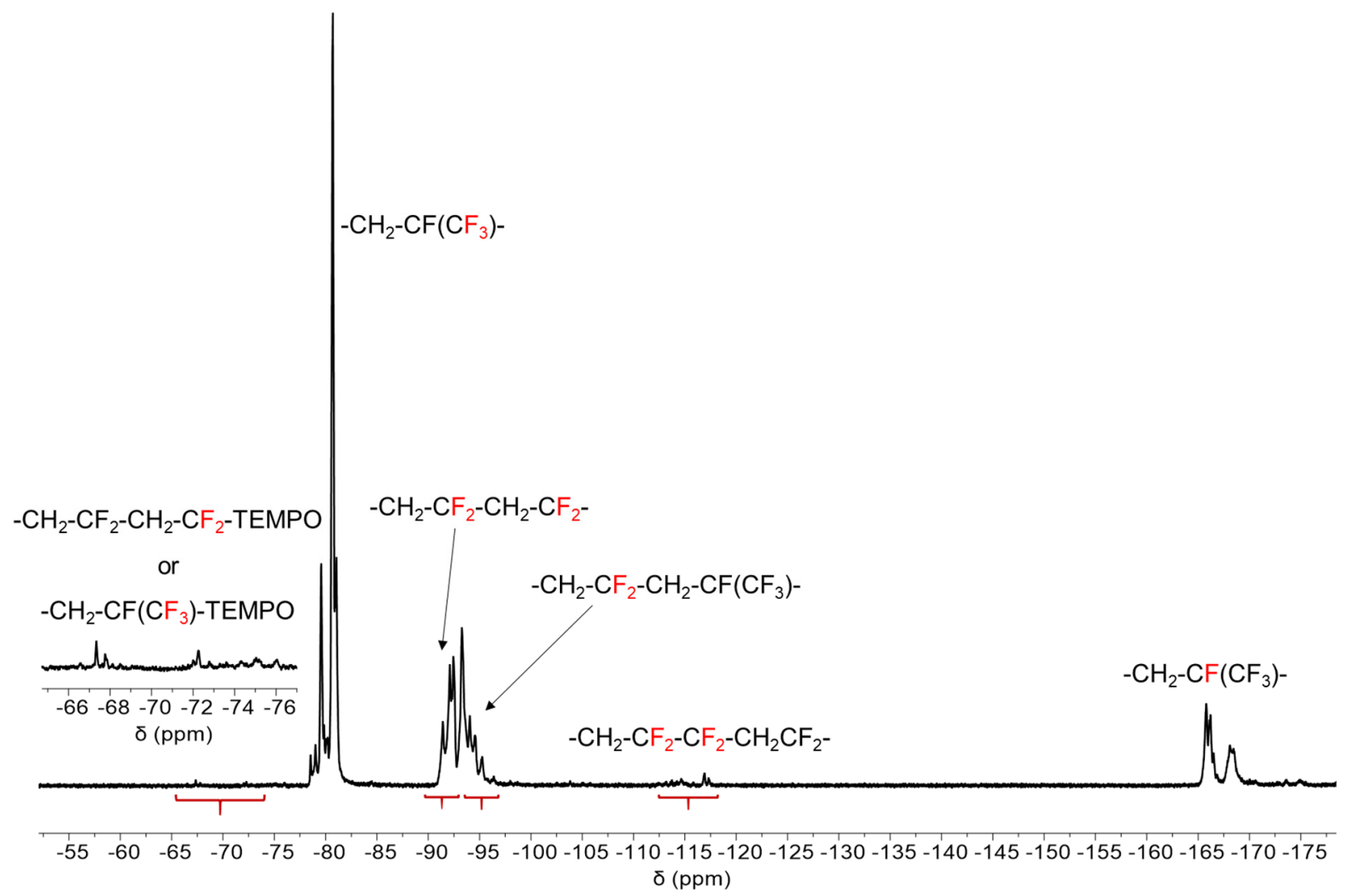

Figure 3. ${ }^{19} \mathrm{~F}$ NMR spectrum recorded in $\left(\mathrm{CD}_{3}\right)_{2} \mathrm{CO}$ of $\mathrm{P}(\mathrm{VDF}-\mathrm{co}-1234 \mathrm{yf})$ copolymer synthesized via $\mathrm{OMRP}$ at $60^{\circ} \mathrm{C}(\mathrm{Table} 1$, Entry 8).

Table 1. Results on the kinetics of the copolymerization of VDF with 1234yf via OMRP. Conditions $[\mathrm{VDF}]_{0} /[1234 \mathrm{yf}]_{0} /[\mathrm{P} 16]_{0} /\left[\mathrm{Co}(\mathrm{acac})_{2}\right]_{0}=80 / 20 / 2 / 1$ at $\mathrm{T}=60^{\circ} \mathrm{C}$.

\begin{tabular}{ccccc}
\hline Entry & Polymerization Time (h) & Conv. (\%) & $\left.\boldsymbol{M}_{\boldsymbol{n}} \mathbf{( g / m o l}\right)^{\mathbf{b}}$ & $\mathbf{\Xi}^{\mathbf{b}}$ \\
\hline 1 & 0.25 & 12 & 6500 & 1.33 \\
2 & 0.5 & 13 & 6800 & 1.16 \\
3 & 0.75 & 15 & 7700 & 1.32 \\
4 & 1 & 18 & 8600 & 1.34 \\
5 & 2 & 26 & 10,300 & 1.29 \\
6 & 4 & 27 & 11,000 & 1.36 \\
7 & 6 & 30 & 11,500 & 1.39 \\
8 & 8 & 33 & 12,200 & 1.47 \\
\hline
\end{tabular}

a The conversion was calculated gravimetrically, ${ }^{\mathrm{b}}$ number of average molar mass and dispersity of the copolymers measured by GPC relative to poly(methyl methacrylate) standards in DMF at $40{ }^{\circ} \mathrm{C}$.

Additionally, the monomer reactivity ratios of the copolymers prepared by OMRcP were determined via the correlation of the copolymer-monomer feed composition relationship. Therefore, a series of seven $\mathrm{P}(\mathrm{VDF}-\mathrm{co}-1234 \mathrm{yf})$ copolymers was carried out by OMRcP from initial $[\mathrm{VDF}]_{0} /[1234 \mathrm{yf}]_{0}$ molar ratios ranging from $90 / 10$ to $16 / 84$ in $\mathrm{DMC}$ at $60{ }^{\circ} \mathrm{C}$ using a predetermined amount of $\mathrm{P} 16$ and $\mathrm{Co}\left(\mathrm{acac}_{2}\right)$ of which the molar ratio was always maintained at $2 / 1$. The copolymer conversion was limited to less than $10-15 \%$ to minimize the drift of copolymer formation. The VDF molar fraction contained in the copolymer was assessed from ${ }^{19}$ F-NMR spectra based on Equation (1) (Figure 4, Table 2). 


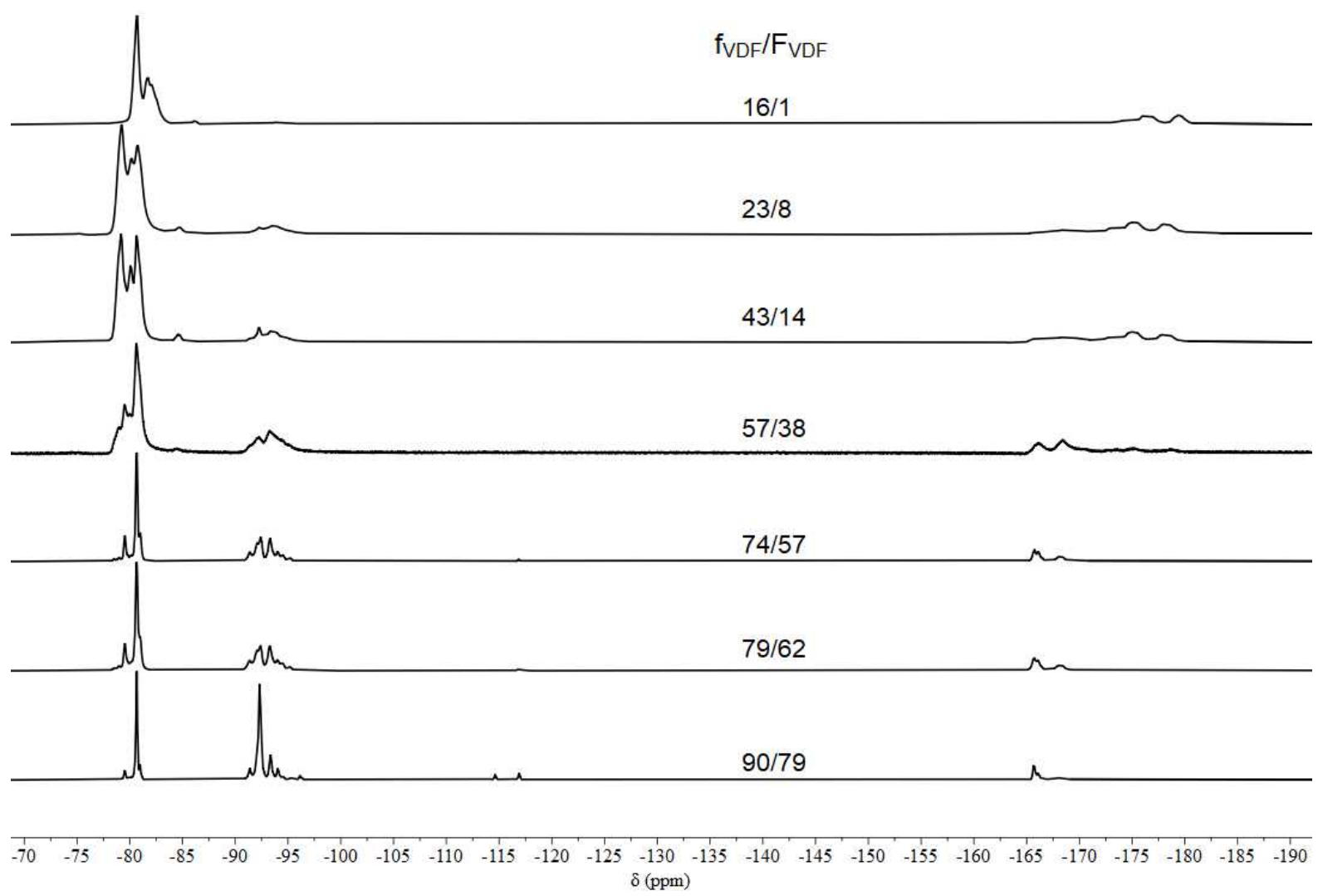

Figure 4. Stack of ${ }^{19} \mathrm{~F}$ NMR spectra recorded at $25{ }^{\circ} \mathrm{C}$ in $\left(\mathrm{CD}_{3}\right)_{2} \mathrm{CO}$ of seven $\mathrm{P}(\mathrm{VDF}-\mathrm{co}-1234 \mathrm{yf})$ copolymers. The polymerizations were stopped at low monomer conversion $(<10 \%)$.

Table 2. Compositions of the feed (f, mol fraction) and composition (F, mol fraction) in the P(VDF-co1234yf) copolymer.

\begin{tabular}{cccc}
\hline $\mathbf{f}_{\text {VDF }}$ & $\mathbf{f}_{\mathbf{1 2 3 4} \mathbf{y f}}$ & $\mathbf{F}_{\mathbf{V D F}}$ & $\mathbf{F}_{\mathbf{1 2 3 4}}$ \\
\hline 90 & 10 & 79 & 21 \\
79 & 21 & 62 & 38 \\
74 & 26 & 57 & 43 \\
57 & 43 & 38 & 62 \\
43 & 57 & 14 & 86 \\
23 & 77 & 8 & 92 \\
16 & 84 & 1 & 99 \\
\hline
\end{tabular}

It is obvious from the above analysis that the mole fraction of VDF in the copolymers is lower than in the feed $\left(f_{\mathrm{VDF}}>\mathrm{F}_{\mathrm{VDF}}\right)$. This result clearly indicates that there is a significant difference in the reactivity ratios between the fluoromonomers. The reactivity ratios of VDF and 1234yf were determined by applying the Fineman-Ross [28] (Figure 5a) and Kelen-Tüdös [29] (Figure 5b) approaches. It is clear that regardless of the method chosen to estimate such parameters, the obtained data is rather similar in each case (Table 3). Specifically, the reactivity ratios are equal to $\mathrm{r}_{\mathrm{vdf}}=0.384 \pm 0.013, \mathrm{r}_{1234 \mathrm{yf}}=2.147 \pm 0.129$ at $60{ }^{\circ} \mathrm{C}$. As can be concluded from the calculations, the reactivity ratio of $1234 \mathrm{yf}$ is, in every case, significantly higher than that of VDF. The latter signifies that VDF propagation is not preferred in contrast to VDF and 1234yf cross-propagation while on the other hand, $1234 y f$ prefers to undergo a homopolymerization rather than a copolymerization. Additionally, the product of the reactivity ratios for the copolymerization of VDF with $1234 \mathrm{yf}$ $\left.\left(\mathrm{r}_{\mathrm{vdf}} \times \mathrm{r}_{1234 \mathrm{yf}}\right)=0.8\right)$ is close to 1 , indicating a slight deviation from random polymerization kinetics and the formation of gradient copolymers of $\mathrm{P}(\mathrm{VDF}-\mathrm{co}-1234 \mathrm{yf})$ copolymers. These results are in agreement with those of the literature in previous studies on P(VDF-co-1234yf) 
copolymers synthesized by iodine transfer polymerization and free radical polymerization where VDF is frequently reported as a less reactive monomer in copolymerization procedures [13,15], except with hexafluoropropylene [30] and perfluoromethylvinyl ether [31].
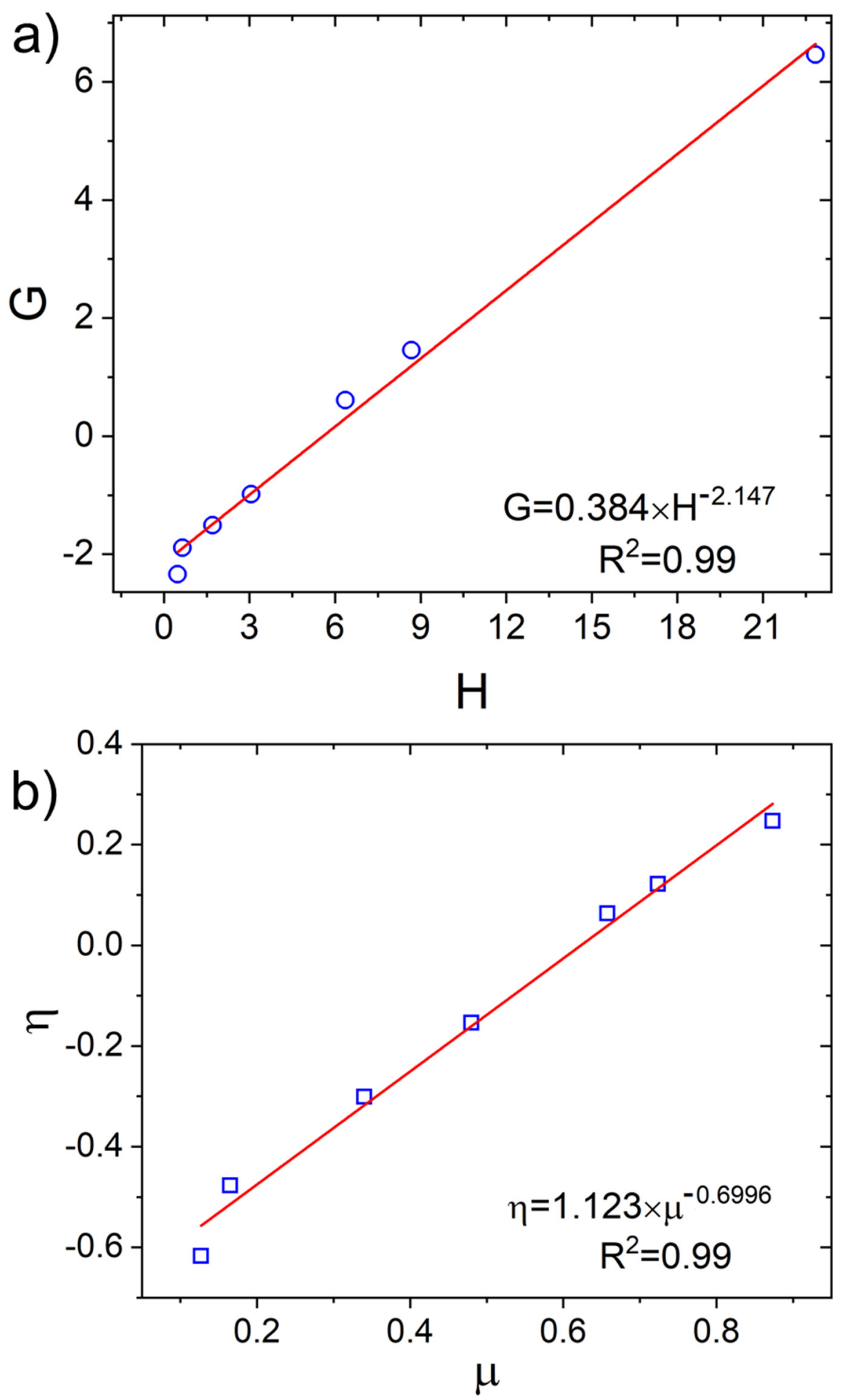

Figure 5. Determination of reactivity ratios for the CMRP of VDF and 1234yf by (a) Fineman-Ross and (b) Kelen-Tüdös models by $\mathrm{OMRcP}$ mediated by $\mathrm{Co}(\mathrm{acac})_{2}$ and initiated by bis(tert-butylcyclohexyl) peroxydicarbonate (P16). 
Table 3. Reactivity ratios of VDF and 1234yf determined at $60^{\circ} \mathrm{C}$ in DMC using initiated by P16 in the presence of $\mathrm{Co}(\mathrm{acac})_{2}$.

\begin{tabular}{cc}
\hline Method & VDF/1234yf \\
\hline Fineman-Ross & $\mathrm{r}_{\mathrm{vdf}}=0.384 \pm 0.013, \mathrm{r}_{1234 y f}=2.147 \pm 0.129$ \\
Kelen-Tüdös & $\mathrm{r}_{\mathrm{vdf}}=0.434 \pm 0.054, \mathrm{r}_{1234 \mathrm{yf}}=2.285 \pm 0.054$ \\
\hline
\end{tabular}

The parameters of specific reactivity $(\mathrm{Q})$ and polarity (e) of a monomer refer to its stabilization by resonance and polar effects, respectively. To the best of our knowledge, as never reported in the literature, such parameters can be calculated for 1234yf using Alfrey and Price equations (Equations (1) and (2)) [32].

$$
\begin{gathered}
r_{V D F}=\frac{Q_{V D F}}{Q_{1234 y f}} \exp \left[-e_{V D F}\left(e_{V D F}-e_{1234 y f}\right]\right. \\
r_{1234 y f}=\frac{Q_{1234 y f}}{Q_{V D F}} \exp \left[-e_{1234 y f}\left(e_{1234 y f}-e_{V D F}\right)\right]
\end{gathered}
$$

According to the literature, Q-e values of VDF have been reported to be 0.015 and 0.5, respectively [33]. These values, incorporated in Equations (1) and (2), enable the calculation of the respective Q-e values of $1234 \mathrm{yf}$ as follows: $\mathrm{Q}_{1234 \mathrm{yf}}=0.04$ and $\mathrm{e}_{1234 \mathrm{yf}}=0.94$ and $\mathrm{Q}_{1234 \mathrm{yf}}=0.03$ and $\mathrm{e}_{1234 \mathrm{yf}}=0.06$. As expected, a positive $\mathrm{e}_{1234 \mathrm{yf}}$ confirms that this monomer is electron-withdrawing (or acceptor), characteristic of fluoroalkenes, while a $\mathrm{Q}_{1234 \mathrm{yf}}$ value much higher than $\mathrm{Q}_{V D F}$ highlights a higher reactivity than VDF (or a lower activity of VDF growing radical).

The reactivity of each monomer can be illustrated by the statistical distribution of the dyad monomer sequences as VDF-VDF, 1234yf-1234yf, and VDF-1234yf, calculated according to the Igarashi method [34] based on Equations (3)-(5) (where $\varphi_{\mathrm{VDF}}$ represents the VDF mole fraction in the copolymer).

$$
\begin{gathered}
\mathrm{f}_{\mathrm{VDF}-\mathrm{VDF}}=\varphi_{\mathrm{VDF}}-\frac{2 \varphi_{\mathrm{VDF}}\left(1-\varphi_{\mathrm{VDF}}\right)}{1+\sqrt{\left[\left(2 \varphi_{\mathrm{VDF}}-1\right)^{2}+4 \mathrm{r}_{\mathrm{VDF}} \mathrm{r}_{1234 \mathrm{yf}} \varphi 1234 \mathrm{yf}\left(1-\varphi_{\mathrm{VDF}}\right)\right]}} \\
\mathrm{f}_{1234 \mathrm{yf}-1234 \mathrm{yf}}=1-\varphi_{\mathrm{VDF}}-\frac{2 \varphi_{\mathrm{VDF}}\left(1-\varphi_{\mathrm{VDF}}\right)}{1+\sqrt{\left[\left(2 \varphi_{\mathrm{VDF}}-1\right)^{2}+4 \mathrm{r}_{\mathrm{VDF}} \mathrm{r}_{1234 \mathrm{yf}} \varphi 1234 \mathrm{yf}\left(1-\varphi_{\mathrm{VDF}}\right)\right]}} \\
\mathrm{f}_{\mathrm{VDF}-1234 \mathrm{yf}}=1-\varphi_{\mathrm{VDF}}-\frac{4 \varphi_{\mathrm{VDF}}\left(1-\varphi_{\mathrm{VDF}}\right)}{1+\sqrt{\left[\left(2 \varphi_{\mathrm{VDF}}-1\right)^{2}+4 \mathrm{r}_{\mathrm{VDF}} \mathrm{r}_{1234 \mathrm{yf}} \varphi 1234 \mathrm{yf}\left(1-\varphi_{\mathrm{VDF}}\right)\right]}}
\end{gathered}
$$

Mean sequence lengths PVDF and P1234yf were also calculated using the Equations (6) and (7) [35].

$$
\begin{gathered}
\mu_{\mathrm{VDF}}=1+\mathrm{r}_{\mathrm{VDF}}\left(\frac{\mathrm{M}_{\mathrm{VDF}}}{\mathrm{M}_{1234 \mathrm{yf}}}\right) \\
\mu_{1234 \mathrm{yf}}=1+\mathrm{r}_{1234 \mathrm{yf}}\left(\frac{\mathrm{M}_{1234 \mathrm{yf}}}{\mathrm{M}_{\mathrm{VDF}}}\right)
\end{gathered}
$$

The data are summarized in Table 4, whereas Figure 6 displays the variation of the dyad fractions versus the $1234 \mathrm{yf}$ mole fraction in the copolymer. 
Table 4. Structural data (monomer dyads and mean sequence lengths of PVDF and P1234yf) for the statistical P(VDF-co1234yf) copolymers.

\begin{tabular}{|c|c|c|c|c|c|c|}
\hline$F_{\text {VDF }}$ & $F_{1234 y f}$ & VDF-VDF & $1234 y f-1234 y f$ & VDF-1234yf & $\mu_{\mathrm{VDF}}$ & $\mu_{1234 \mathrm{yf}}$ \\
\hline 0.79 & 0.21 & 0.5977 & 0.0177 & 0.3846 & 2.4445 & 1.5707 \\
\hline 0.62 & 0.38 & 0.3454 & 0.1054 & 0.5491 & 1.6265 & 2.3159 \\
\hline 0.57 & 0.43 & 0.2899 & 0.1498 & 0.5603 & 1.5090 & 2.6196 \\
\hline 0.38 & 0.62 & 0.1921 & 0.4321 & 0.3758 & 1.2353 & 4.5030 \\
\hline 0.14 & 0.86 & 0.0821 & 0.8021 & 0.1158 & 1.0625 & 14.1887 \\
\hline 0.08 & 0.92 & 0.0482 & 0.8882 & 0.0636 & 1.0333 & 25.6905 \\
\hline 0.01 & 0.99 & 0.0062 & 0.9862 & 0.0076 & 1.0038 & 213.5535 \\
\hline
\end{tabular}

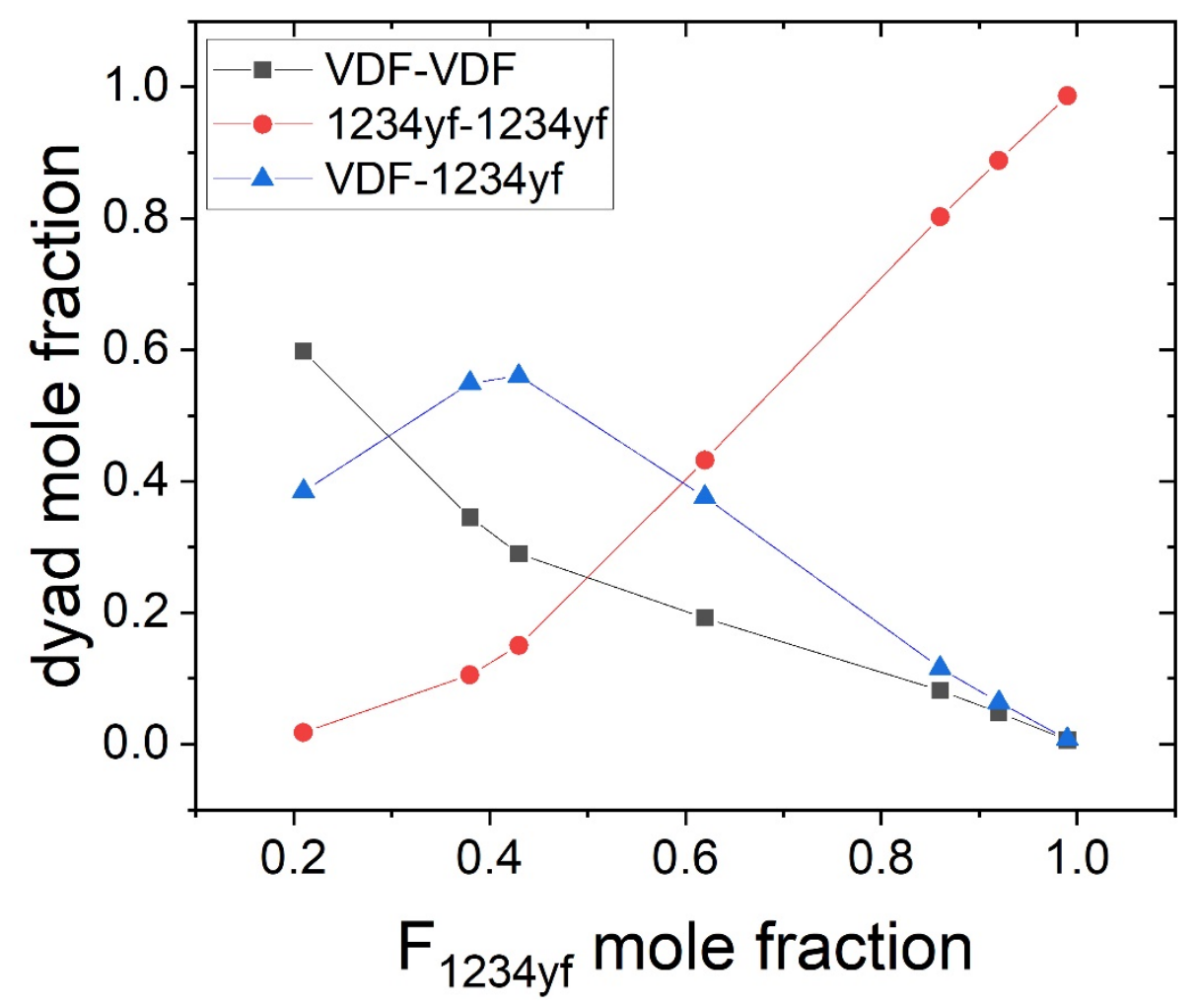

Figure 6. Dyad monomer sequence fractions versus the $1234 \mathrm{yf}$ mole fraction for the P(VDF-co1234yf) copolymers.

Figure 6 displays the variations of the dyad fractions versus the $1234 \mathrm{yf}$ mole fraction in the P(VDF-co-1234yf) copolymer. The results show that the mole fraction of the VDFVDF dyad is constantly decreasing as the $1234 \mathrm{yf}$ mole fraction increases, while the same trend was also observed for VDF-1234yf dyads. On the other hand, the mole fraction of $1234 y f-1234 y f$ dyads increased gradually with 1234yf mole fraction. The above trend is a clear evidence of a great difference of monomer reactivity which was also verified by the calculation of the reactivity ratios values for the corresponding monomers.

\section{Experimental Section}

\subsection{Materials and Methods}

1,1-Difluoroethylene (VDF) and 2,3,3,3-tetrafluoropropene (1234yf) were kindly supplied by Arkema (Pierre-Bénite, France). Bis(tert-butylcyclohexyl) peroxydicarbonate (Perkadox ${ }^{\circledR}$ 16, P16, 90\%,) was obtained from AkzoNobel, reagentPlus grade; dimethyl carbonate (DMC, >99\%, Merk, Darmstadt, Germany), Cobalt(II) acetylacetonate (Co(acac) ${ }_{2}$, 97\%), 2,2,6,6-tetramethylpiperidine 1-oxy (TEMPO, 98\%), and n-pentane (95\%) were purchased from Sigma Aldrich and used as received. Deuterated acetone (acetone- $d_{6}$ ) 
(purity $>99.8 \%$ ) used for ${ }^{1} \mathrm{H}$ and ${ }^{19} \mathrm{~F}$ NMR spectroscopy was purchased from Euroiso-top (Grenoble, France).

\subsection{Characterizations}

\subsubsection{Nuclear Magnetic Resonance (NMR) Spectroscopy}

${ }^{19} \mathrm{~F}$ NMR spectra were recorded on a Bruker AC 400 Spectrometer $\left(376 \mathrm{MHz}\right.$ for $\left.{ }^{19} \mathrm{~F}\right)$ using acetone- $d_{6}$ as solvent. The sample temperature was set to $298 \mathrm{~K}$. Chemical shifts and coupling constants are given in Hertz $(\mathrm{Hz})$ and parts per million $(\mathrm{ppm})$, respectively. The experimental conditions for recording the ${ }^{19} \mathrm{~F}$ NMR spectra were as follows: flip angle $30^{\circ}$, acquisition time $0.7 \mathrm{~s}$, pulse delay $5 \mathrm{~s}$, number of scans 64 , and a pulse width of $5 \mu \mathrm{s}$ for ${ }^{19} \mathrm{~F}$ NMR.

\subsubsection{Gel Permeation Chromatography (GPC)}

The apparent numbers of average molar masses and dispersities of the synthesized polymers were determined using a GPC system (Varian 390-LC) multi-detector equipped with a differential refractive index detector (RI), using a guard column (Varian Polymer Laboratories, Church Stratton, UK, PLGel $5 \mu \mathrm{m}, 50 \times 7.5 \mathrm{~mm}$ ), and two ResiPore columns of the same type. The mobile phase was DMF with $0.1 \mathrm{wt} \% \mathrm{LiBr}$ adjusted at a flow rate of $1 \mathrm{~mL} \mathrm{~min}{ }^{-1}$ while the columns were thermostated at $70{ }^{\circ} \mathrm{C}$. The GPC system was calibrated using narrow poly(methyl methacrylate) (PMMA) standards ranging from 550 to 1,568,000 g/mol (EasiVial-Agilent, Stockpor, Cheshire, UK).

\subsubsection{OMRP of VDF with $1234 y f$ Initiated by P16 in the Presence of Co(acac $)_{2}$}

The copolymerization of VDF with 1234yf was performed in a $50 \mathrm{~mL}$ Hastelloy autoclave Parr system (HC 276) equipped with a manometer, a mechanical Hastelloy anchor, a rupture disk (3000 PSI), inlet and outlet valves equipped with a special steel pipe, and a Parr electronic controller (for stirring speed and heating control). Prior to the introduction of the mixture solution, the autoclave was checked for any leaks by performing three vacuum-nitrogen cycles before finally applying vacuum $\left(40 \times 10^{-6}\right.$ bar) for $30 \mathrm{~min}$ to remove any residual traces of oxygen. A typical copolymerization of VDF with 1234yf by OMRP mediated by $\mathrm{Co}(\mathrm{acac})_{2}$ was performed as follows (Table 1, Entry 8): initially, $\mathrm{Co}(\mathrm{acac})_{2}(0.40 \mathrm{~g}, 1.55 \mathrm{mmol})$ was introduced into the autoclave and then the reactor was closed and put under vacuum $\left(10^{-2} \mathrm{mbar}\right)$ so as to remove any residual traces of oxygen. Then, a degassed solution of DMC $(30 \mathrm{~mL})$ was transferred through a funnel tightly connected to the inlet valve of the autoclave. The reactor was then cooled in a liquid nitrogen bath, and subsequently VDF $(8.34 \mathrm{~g}, 0.130 \mathrm{~mol})$ and $1234 \mathrm{yf}(1.65 \mathrm{~g}, 0.014 \mathrm{~mol})$ gases were introduced in sequence under weight control. Subsequently, the autoclave was progressively warmed up to $60{ }^{\circ} \mathrm{C}$ while the reaction solution was mechanically stirred. The polymerization was triggered by the introduction of a degassed solution of P16 $(1.24 \mathrm{~g}, 3.11 \mathrm{mmol})$ in DMC $(10 \mathrm{~mL})$ in the reactor using an HPLC pump $(5.0 \mathrm{~mL} / \mathrm{min})$. The copolymerization was conducted for $24 \mathrm{~h}$ and then was quenched by transferring (via a HPLC pump) a nitrogen-purged solution of TEMPO $(0.480 \mathrm{~g}, 3.11 \mathrm{mmol}, 2$ equivalents with respect to $\left.\mathrm{Co}(\mathrm{acac})_{2}\right)$ in $\mathrm{DMC}(5 \mathrm{~mL})$ into the autoclave and letting it react for $30 \mathrm{~min}$ at $64{ }^{\circ} \mathrm{C}$, according to a previously reported procedure [1]. Finally, the autoclave was immersed in an ice bath, depressurized by venting, and opened to air. The purified copolymer was obtained after two repeated precipitations in 10-fold excess $(400 \mathrm{~mL})$ of chilled pentane and it was recovered by filtration followed by drying under vacuum overnight. The final product was recovered as a white powder ( $3.70 \mathrm{~g}, 34 \%$ yield) (in the case of higher $1234 \mathrm{yf}$ contents, whitish gums were produced) and characterized by ${ }^{19} \mathrm{~F}$ NMR spectroscopy and gel permeation chromatography. At this point, it should be mentioned that the polymerization yield was assumed identical as the monomer conversion, since it is particularly difficult to experimentally determine the comonomers conversion.

${ }^{19} \mathrm{~F}$ NMR (376 MHz, acetone- $\mathrm{d}_{6}, \delta(\mathrm{ppm})$, Figure 3): from -78 to $-82\left(-\mathrm{CFF}_{3}\right.$ of $1234 \mathrm{yf}$ in the copolymer), from -90.6 to $-95.4\left(-\mathrm{CH}_{2} \mathrm{CFF}_{2} \mathrm{CH}_{2} \mathrm{CFF}_{2}^{-}\right.$, normal addition of VDF); 
-95.4 to $-92.7\left(-\mathrm{CH}_{2} \mathrm{CF}_{2}-\mathrm{CH}_{2} \mathrm{CF}\left(\mathrm{CF}_{3}\right)-\right)-114\left(-\mathrm{CH}_{2} \mathrm{CFF}_{2}-\mathrm{CF}_{2} \mathrm{CH}_{2}-\mathrm{CH}_{2}\right.$, reverse addition of VDF); $-116\left(-\mathrm{CH}_{2} \mathrm{CF}_{2}-\mathrm{CFF}_{2} \mathrm{CH}_{2}-\mathrm{CH}_{2}\right.$, reverse addition of VDF); -165 (tertiary fluorine $-\mathrm{CFF}\left(\mathrm{CF}_{3}\right)$ of $\left.1234 \mathrm{yf}\right)$.

\subsubsection{Determination of the Reactivity Ratios of VDF and $1234 \mathrm{yf}$}

In order to determine the reactivity ratios of VDF and 1234yf by OMRP, seven copolymerizations were performed at different feed monomer compositions, with the VDF feed composition ( $\mathrm{f}_{\mathrm{VDF}}$ ) ranging from 0.16 to 0.90 (Table 2). Initially, solutions containing appropriate amounts of $\mathrm{Co}(\mathrm{acac})_{2}, \mathrm{P} 16$, and $\mathrm{DMC}$ were transferred via a metal syringe into a borosilicate Carius tube (length, $130 \mathrm{~mm}$; internal diameter, $18 \mathrm{~mm}$; thickness, $2.5 \mathrm{~mm}$; total volume, $16 \mathrm{~cm}^{3}$ ). The Carius tubes were then cooled in a liquid nitrogen bath and predetermined amounts of VDF and 1234yf gaseous monomers were transferred into the frozen tubes using a custom-made manifold that enables accurate measurement of the quantity of the gas (using "pressure drop versus mass of monomer" calibration curves). In all polymerization reactions, the concentration of the gaseous monomers to solvent was kept constant to $0.42 \mathrm{~g} / \mathrm{mL}$ in order to ensure similar polymerization conditions. Subsequently, the bottleneck of the tubes was flame-sealed while keeping the content frozen in a liquid $\mathrm{N}_{2}$ bath. The polymerizations were started by immersing the tubes in a preheated and shaking bath thermostated at $60^{\circ} \mathrm{C}$. All copolymerizations were stopped after $15 \mathrm{~min}$ by freezing the tubes into liquid nitrogen and then opened to air, in order to ensure that the overall conversion of monomers was lower than $10 \%$. The total product mixture was recovered, dried under vacuum overnight and characterized by ${ }^{19} \mathrm{~F}$ NMR spectroscopy in acetode- $\mathrm{d}_{6}$ for the determination of the molar fraction of VDF in the copolymer $\left(\mathrm{F}_{\mathrm{VDF}}\right)$ molar copolymer compositions (Figure 4 displays the stack of the ${ }^{19} \mathrm{~F}$ NMR spectra of all experiments).

\subsubsection{Determination of Reactivity Ratios with the Fineman-Ross and Kelen-Tüdös Model}

The molar fractions of VDF base units in the copolymer were determined using Equation (1) by taking the ratios of the integrals of all signals of $-\mathrm{CF}_{2}$ in VDF monomer units with respect to those of the signals of $-\mathrm{CF}_{3}$ in $1234 \mathrm{yf}$ units in the ${ }^{19} \mathrm{~F}$ NMR spectra:

$$
\text { mol\% VDF in copolymers }=\frac{\left(\int_{-91}^{-96} \mathrm{CF}_{2}+\int_{-113}^{-118} \mathrm{CF}_{2}\right) / 2}{\left(\int_{-91}^{-96} \mathrm{CF}_{2}+\int_{-113}^{-118} \mathrm{CF}_{2}\right) / 2+\int_{-82}^{-84} \mathrm{CF}_{3} / 3} \times 100
$$

The reactivity ratios were determined by applying mathematical models of copolymerization which correlate the relationship between the composition of the monomer feed $\left(\mathrm{f}_{\mathrm{VDF}}\right)$ and the composition of the copolymers $\left(\mathrm{F}_{\mathrm{VDF}}\right)$. In the present study, Fineman-Ross (FR) and Kelen-Tüdös (KT) fitting curve methods were applied for the accurate calculation of the reactivity ratios. The former is expressed by Equation (2).

$$
G=H \times r_{1}-r_{2}
$$

Plotting $G=\frac{f_{1}\left(2 F_{1}-1\right)}{\left(1-f_{1}\right) F_{1}}$ as ordinate versus $H=\frac{f_{1}^{2}\left(1-F_{1}\right)}{\left(1-f_{1}\right)^{2} F_{1}}$ as abscissa yields a straight line, the slope of which represents $r_{1}$ value while the intercept is $-r_{2}$ value. The KelenTüdös method employs the following Equation (3):

$$
\eta=\left[\frac{r 1+r_{2}}{\alpha}\right] \mu-\frac{r_{2}}{\alpha}
$$

involving $\eta$ and $\mu$ parameters which are mathematical functions related to the mole ratios in the monomer feed and in the copolymer and an arbitrary constant $\alpha$. Such parameters are defined as $\eta=\frac{G}{(a+H)}$ and $\mu=\frac{H}{(\alpha+H)}$ and $\alpha=\left(H_{\min } H_{\max }\right)^{0.5}$, where $H_{\text {min }}$ and $H_{\text {max }}$ are the highest and lowest values of $H$ from the Fineman-Ross method. Thus, a plot of $\eta$ versus 
$\mu$ gives a straight line which can be extrapolated at $\mu=0$ and $\mu=1$, thereby yielding $\frac{r_{2}}{a}$ and $r_{1}$ as the respective $\eta$ intercepts.

\section{Conclusions}

For the first time, the OMR copolymerization of VDF and 1234yf initiated by the presence of P16 using $\mathrm{Co}(\mathrm{acac})_{2}$ as a controlling agent was successfully conducted. Polymerization kinetic was found to lead to an acceptable control under optimized conditions $\left([\mathrm{P} 16]_{0} /\left[\mathrm{Co}(\mathrm{acac})_{2}\right]_{0}=2 / 1, \mathrm{~T}=60{ }^{\circ} \mathrm{C}\right)$, leading to $\mathrm{P}(\mathrm{VDF}-\mathrm{co}-1234 \mathrm{yf})$ copolymers with relatively low dispersities $(\mathrm{D}<1.47)$ until conversion up to $33 \%$. The molar masses of such copolymers, determined by GPC, increased linearly with the monomer conversions. The reactivity ratios of both comonomers were calculated based on Fineman-Ross and Kelen-Tüdös models where similar ratios were obtained in both cases: $r_{\mathrm{VDF}}=0.384 \pm 0.013$ and $\mathrm{r}_{1234 \mathrm{yf}}=2.147 \pm 0.129$ at $60^{\circ} \mathrm{C}$, denoting that $1234 \mathrm{yf}$ is more reactive than VDF, thus likely favoring the formation of gradient copolymers. The result is in agreement with the dyad statistical distribution in the copolymers. Finally, the Q-e values could also be calculated for the first time. The above results demonstrate that $\mathrm{Co}(\mathrm{acac})_{2}$-mediated controlled radical copolymerization of VDF and 1234yf initiated by P16 is possible. Finally, future works will look more closely into further optimization of this synthetic strategy which could open the route towards the synthesis of well-defined block terpolymers that will offer the desired combination of properties for advanced applications.

Author Contributions: P.G.F. carried out the experiments and wrote the frist draft of manuscript; B.A. supervised P.G.F., discussed results with him and corrected the drafts. Both authors have read and agreed to the published version of the manuscript.

Funding: This research was funded by French National Agency (ANR) grant: ANR-14-CE07-0012-02 FLUPOL project.

Institutional Review Board Statement: Not applicable.

Informed Consent Statement: Not applicable.

Acknowledgments: The authors thank Arkema (Pierre Bénite, France) for providing VDF and 1234yf gases and the French National Agency (ANR ANR-14-CE07-0012-02 FLUPOL project) for supporting this study, as well as R. Poli, V. Ladmiral, A. Debuigne, and C. Detrembleur for fruitful discussions.

Conflicts of Interest: The authors declare no conflict of interest.

\section{References}

1. Smith, D.W.; Iacono, S.T.; Iyer, S.S. Handbook of Fluoropolymer Science and Technology; Wiley: New York, NY, USA, 2014.

2. Goldbach, J.T.; Amin-Sanayei, R.; He, W.; Henry, J.; Kosar, W.; Lefebvre, A.; O’Brien, G.; Vaessen, D.; Wood, K.; Zerafati, S. Chapter 6 Commercial Synthesis and Applications of Poly(Vinylidene Fluoride). In Fluorinated Polymers: Volume 2: Applications; The Royal Society of Chemistry: London, UK, 2017; Volume 2, pp. 127-157.

3. Ameduri, B.; Fomin, S. Fascinating Fluoropolymers and Their Applications; Elsevier: Oxford, UK, 2020; p. 494.

4. Ebnesajjad, S. Non-Melt Processible Fluoroplastics; William Andrew Publishing: Norwich, UK; New York, NY, USA, 2000.

5. Puts, G.J.; Crouse, P.; Ameduri, B.M. Polytetrafluoroethylene: Synthesis and Characterization of the Original Extreme Polymer. Chem. Rev. 2019, 119, 1763-1805. [CrossRef]

6. Ameduri, B. From Vinylidene Fluoride (VDF) to the Applications of VDF-Containing Polymers and Copolymers: Recent Developments and Future Trends. Chem. Rev. 2009, 109, 6632-6686. [CrossRef]

7. Asandei, A.D. Photomediated Controlled Radical Polymerization and Block Copolymerization of Vinylidene Fluoride. Chem. Rev. 2016, 116, 2244-2274. [CrossRef]

8. Costa, C.M.; Silva, M.M.; Lanceros-Méndez, S. Battery separators based on vinylidene fluoride (VDF) polymers and copolymers for lithium ion battery applications. RSC Adv. 2013, 3, 11404-11417. [CrossRef]

9. Velders, G.J.M.; Fahey, D.W.; Daniel, J.S.; Andersen, S.O.; McFarland, M. Future atmospheric abundances and climate forcings from scenarios of global and regional hydrofluorocarbon (HFC) emissions. Atmos. Environ. 2015, 123, 200-209. [CrossRef]

10. Velders, G.J.M.; Fahey, D.W.; Daniel, J.S.; McFarland, M.; Andersen, S.O. The large contribution of projected HFC emissions to future climate forcing. Proc. Natl. Acad. Sci. USA 2009, 106, 10949-10954. [CrossRef]

11. WMO (World Meteorological Organization). Scientific Assessment of Ozone Depletion: 2018; Global Ozone Research and Monitoring Project-Report No. 58; World Meteorological Organization: Geneva, Switzerland, 2018; p. 588. 
12. Patil, Y.; Alaaeddine, A.; Ono, T.; Ameduri, B. Novel Method to Assess the Molecular Weights of Fluoropolymers by Radical Copolymerization of Vinylidene Fluoride with Various Fluorinated Comonomers Initiated by a Persistent Radical. Macromolecules 2013, 46, 3092-3106. [CrossRef]

13. Soulestin, T.; Ladmiral, V.; Lannuzel, T.; Santos, F.D.D.; Améduri, B. Differences in electroactive terpolymers based on VDF, TrFE and 2,3,3,3-tetrafluoropropene prepared by batch solution and semi-continuous aqueous suspension polymerizations. Polym. Chem. 2017, 8, 735-747. [CrossRef]

14. Durali, M.C.; Mountz, D.A. Vinylidene Fluoride/2,3,3,3-Tetrafluoropropene Copolymers. U.S. Patent 10,259,899, 16 April 2019.

15. Banerjee, S.; Zaghloul, S.; Alaaeddine, A.; Ameduri, B. Kinetic and mechanistic aspects of the iodine transfer copolymerization of vinylidene fluoride with 2,3,3,3-tetrafluoro-1-propene and functionalization into $\omega$-hydroxy fluorinated copolymers. Polym. Chem. 2016, 7, 6099-6109. [CrossRef]

16. Ameduri, B.; Alaaeddine, A. Controlled Radical Copolymerization of Trifluoroethylene. U.S. Patent 2017/9708419, 18 July 2021.

17. Falireas, P.G.; Ladmiral, V.; Debuigne, A.; Detrembleur, C.; Poli, R.; Ameduri, B. Straightforward Synthesis of Well-Defined Poly(vinylidene fluoride) and Its Block Copolymers by Cobalt-Mediated Radical Polymerization. Macromolecules 2019, 52, 1266-1276. [CrossRef]

18. Banerjee, S.; Ladmiral, V.; Debuigne, A.; Detrembleur, C.; Poli, R.; Améduri, B. Organometallic-Mediated Radical Polymerization of Vinylidene Fluoride. J. Am. Chem. Soc. 2018, 57, 2934-2937. [CrossRef]

19. Demarteau, J.; Debuigne, A.; Detrembleur, C. Organocobalt Complexes as Sources of Carbon-Centered Radicals for Organic and Polymer Chemistries. Chem. Rev. 2019, 119, 6906-6955. [CrossRef]

20. Wang, P.; Wang, H.; Dong, Q.; Bai, R. Cobalt-Mediated Radical Copolymerization of Chlorotrifluoroethylene and Vinyl Acetate. Polymers 2019, 11, 101. [CrossRef] [PubMed]

21. Asandei, A.D.; Adebolu, O.I.; Simpson, C.P. Mild-Temperature Mn2(CO)10-Photomediated Controlled Radical Polymerization of Vinylidene Fluoride and Synthesis of Well-Defined Poly(vinylidene fluoride) Block Copolymers. J. Am. Chem. Soc. 2012, 134, 6080-6083. [CrossRef] [PubMed]

22. Debuigne, A.; Caille, J.-R.; Jérôme, R. Highly Efficient Cobalt-Mediated Radical Polymerization of Vinyl Acetate. Angew. Chem. Int. Ed. 2005, 44, 1101-1104. [CrossRef] [PubMed]

23. Destarac, M.; Matyjaszewski, K.; Silverman, E.; Ameduri, B.; Boutevin, B. Atom Transfer Radical Polymerization Initiated with Vinylidene Fluoride Telomers. Macromolecules 2000, 33, 4613-4615. [CrossRef]

24. Girard, E.; Marty, J.-D.; Ameduri, B.; Destarac, M. Direct Synthesis of Vinylidene Fluoride-Based Amphiphilic Diblock Copolymers by RAFT/MADIX Polymerization. ACS Macro Lett. 2012, 1, 270-274. [CrossRef]

25. Golzari, N.; Adams, J.; Beuermann, S. Inducing $\beta$ Phase Crystallinity in Block Copolymers of Vinylidene Fluoride with Methyl Methacrylate or Styrene. Polymers 2017, 9, 306. [CrossRef]

26. Bryaskova, R.; Detrembleur, C.; Debuigne, A.; Jérôme, R. Cobalt-Mediated Radical Polymerization (CMRP) of Vinyl Acetate Initiated by Redox Systems: Toward the Scale-Up of CMRP. Macromolecules 2006, 39, 8263-8268. [CrossRef]

27. Guerre, M.; Rahaman, S.M.W.; Améduri, B.; Poli, R.; Ladmiral, V. Limits of Vinylidene Fluoride RAFT Polymerization. Macromolecules 2016, 49, 5386-5396. [CrossRef]

28. Fineman, M.; Ross, S.D. Linear method for determining monomer reactivity ratios in copolymerization. J. Polym. Sci. 1950, 5, 259-262. [CrossRef]

29. Kelen, T.; Tüdos, F. Analysis of the Linear Methods for Determining Copolymerization Reactivity Ratios. I. A New Improved Linear Graphic Method. J. Macromol. Sci. Part A Chem. 1975, 9, 1-27. [CrossRef]

30. Hosemann, B.; Siegmann, R.; Beuermann, B. Supercritical Carbon Dioxide as Reaction Medium for Fluoropolymer Synthesis and Kinetic Investigations into Radical Polymerizations of VDF and HFP. In Fluorinated Polymers: Synthesis, Properties Processing and Simulation; Ameduri, B., Sawada, H., Eds.; RSC Polymer Chemistry Series No. 23; The Royal Society of Chemistry: London, UK, 2017; Volume 1, Chapter 7; pp. 211-232.

31. Boyer, C.; Ameduri, B.; Hung, M.H. Telechelic Diiodopoly(VDF-co-PMVE) Copolymers by Iodine Transfer Copolymerization of Vinylidene Fluoride (VDF) with Perfluoromethyl vinyl ether (PMVE). Macromolecules 2010, 43, 3652-3663. [CrossRef]

32. Alfrey, T.; Price, C.C. Relative reactivities in vinyl copolymerization. J. Polym. Sci. 1947, 2, 101-106. [CrossRef]

33. Brandrup, J.; Immergut, E.H.; Grulke, E.A. Polymer Handbook, 4th ed.; Wiley: New York, NY, USA; Chichester, UK, 2004.

34. Igarashi, S. Representation of composition and blockiness of the copolymer by a triangular coordinate system. J. Polym. Sci. Part B Polym. Lett. 1963, 1, 359-363. [CrossRef]

35. Elias, H.G. Macromolecules: Structure and Properties; Plenum Press: New York, NY, USA, 1971; Volume 2. 